\title{
Poverty and Social Exclusion in the European Union
}

\section{Brian Nolan}

\section{Introduction}

Poverty and social inclusion are the central concerns of the European Union's social agenda. This chapter provides an overview of patterns and trends in poverty and social exclusion across the EU, and discusses the factors at work and the challenges they pose. We begin with a discussion of the concepts and measures of poverty and exclusion employed in an EU context. We then look the extent and nature of poverty and social exclusion across the EU before the economic crisis, first as reflected in indicators that rely on household income as the measure of poverty, and then incorporating nonmonetary indicators of deprivation into the picture. The evolution of poverty across the EU (and previously EEC) in the decades up to the crisis is then discussed, before focusing on the impact of the economic crisis. The characteristics and circumstances associated with a heightened risk of being poor are then discussed, before moving on to what appears to underpin the variation in poverty across the member states. We conclude with a brief discussion of the current EU-level orientation on how best to tackle poverty and exclusion.

\section{Poverty, social exclusion and the EU}

Most research on poverty in Europe takes as its point of departure the definition that people are in poverty when "their resources are so seriously below those commanded by the average individual or family that they are, in effect, excluded from ordinary living patterns, customs and activities" - the influential formulation by the British sociologist Peter Townsend (1979, p. 31). The concept of poverty adopted by the European Council in the mid-1980s and underpinning policy formation at European level subsequently was:

"The poor shall be taken to mean persons, families and groups of persons whose resources (material, cultural and social) are so limited as to exclude them from the minimum acceptable way of life in the Member State in which they live".

So poverty from this starting-point has two core elements: it is about inability to participate, and this inability to participate is attributable to inadequate resources. 
While income has most often been used to distinguish the poor, with continuing debate on how best to establish an income cut-off, the widespread adoption from the 1980s of the terminology of social exclusion/inclusion in Europe served to highlighting the barriers and the dynamics of the processes that leave people unable to fully participate in society, as well as the multidimensional nature of such exclusion. Poverty and social exclusion may be seen as inherently multidimensional concepts, involving not only low income/financial resources, but also educational disadvantage, poor health and access to health services, inadequate housing, and exclusion in the labour market. Multidimensional approaches to measuring poverty and social exclusion have been the focus of significant study and debate (see for example Kangas and Ritakallio, 1998, Atkinson, 2003, Bourguignon and Chakravarty, 2003, Kakwani and Silber, 2008, Alkire and Foster, 2011), and this has had an impact on practice at national and EU levels, notably in the use of non-monetary indicators of deprivation often alongside income. It should be noted that seeing poverty and exclusion as multidimensional does not necessarily mean that those in poverty can only be identified using information on a wide range of dimensions: in some circumstances a quite restricted set or even a single indicator (such as income) might prove adequate (Nolan and Whelan, 2007). In this chapter we follow the available research in focusing for the most part on what indicators of low income and deprivation reveal about patterns of poverty in Europe, while also noting studies adopting a more comprehensively multidimensional measurement approach.

The broader evolution of, and challenges to, 'Social Europe' are discussed in detail in the chapters by Daly and Bailey in this Handbook, so here we concentrate on how poverty and social exclusion have been thought about and measured. Empirically, early studies of the extent of poverty for the EU Commission or Eurostat (O'Higgins and Jenkins, 1990, Eurostat, 2000) relied on relative income poverty lines derived as proportions of mean or median income in the country in question to distinguish those in poverty. From 2000 onwards, social protection and inclusion became specific policy areas for EU cooperation, underpinning the development of the Union's Social Inclusion Process in which the monitoring of poverty and social inclusion is embedded. The Open Method of Coordination (OMC) is at the centre, with key elements being the agreement of common objectives, the preparation of National Action Plans and a regular Joint 
Report by the Commission and the Council, and the adoption of common indicators to monitor progress towards the common objectives and compare best practice across Member States. That set of common indicators was adopted at the end of 2001 at the Laeken Council, drawing on the report by Atkinson, Cantillon, Marlier and Nolan, (2002), which emphasised that the portfolio should be balanced across the different dimensions.

The original list of indicators relied heavily on information about income and labour force status where comparative data was already relatively well developed, with indicators based on relative income poverty thresholds playing a particularly important role (described as capturing those 'at risk of poverty' rather than 'poor'). The indicators employed have subsequently been refined and extended in various ways and integrated into the broader 'Social OMC', with Primary indicators now including income poverty risk, unemployment and joblessness, low educational qualifications, access to healthcare, material deprivation, housing and child well-being. These are complemented by Secondary indicators such as poverty risk for different categories and circumstances, and Context Information statistics include income inequality.

Non-monetary deprivation indicators were incorporated into the agreed indicators in 2009 after considerable analysis and debate, with the expansion of the EU from 2004 adding significant impetus since differences in average income per head and in the value of relative poverty thresholds from richest to poorest member states were now very much wider. Material deprivation indicators were seen as helpful in that context, in that a common EU-wide benchmark could be employed, while also helping to address some of the limitations of current income as a measure of resources and living standards. Drawing on research based on EU-SILC (Guio, 2005, 2009, Giuo and Maquet, 2006, Whelan and Maitre, 2005, 2006a) as well as the results of a specially-designed Eurobarometer survey carried out in 2007 (Guio, Fusco and Marlier, 2009), a material deprivation rate showing the percentage living in households that could not afford at least three of nine indicators was included as a primary indicator and "depth of deprivation" showing the average number of these items lacked by those reporting some deprivation was added as a 
secondary indicator. ${ }^{1}$ (Nolan and Whelan, 2011, review and investigate the issues involved in using the available deprivation indicators to best capture poverty and exclusion in Europe.)

With a set of common indicators relating to social inclusion agreed, member states were encouraged to set targets framed in terms of such indicators by the European Commission from the mid-2000s onwards, but only a few member states did so. It was therefore a radical departure when the economic crisis created the impetus for the development of the "Europe 2020" strategy for jobs and growth, formally adopted in mid2010, with five headline targets for the Union as a whole among which is "promoting social inclusion in particular through the reduction of poverty", specifically "to lift at least 20 million people out of the risk of poverty and exclusion". For this purpose the population at risk of poverty and exclusion is defined as those either below the $60 \%$ of median relative income threshold, experiencing severe material deprivation (i.e. deprived on at least 4 out of the 9 deprivation indicators already mentioned), or in a household in which working-age members spent a fifth or less of the available time in the previous year in work. In the EU $17 \%$ of the population were below the income threshold when that target was adopted (or more properly in the data then available, which was for before the crisis), $8 \%$ were above that material deprivation threshold and a similar figure counted as in 'low work intensity' households. With some people captured by more than one criterion, the aggregate EU figure for those "at risk of poverty and exclusion" was $24.5 \%$ of the total population, 120 million people. ${ }^{2}$ In terms of social inclusion, then, the EU now combines what is often referred to as a 'dashboard' approach, where a range of indicators is used to monitor and assess progress, with a single high-level target; ${ }^{3}$ in justifying this approach the EU Commission (2011) has argued that the computation of a multidimensional poverty index is an effective way of communicating in a political

\footnotetext{
${ }^{1}$ The nine items are: being able to pay rent or utility bills; to keep their home adequately warm; to pay unexpected expenses; to eat meat, fish or equivalent every second day; a week's holiday away from home; a car; a washing machine; a colour TV; or a telephone.

${ }^{2}$ Whether this is the best way to frame such a target has been debated, see for example Whelan et al (2014).

${ }^{3}$ The OECD, while focusing for the most part on the analysis of income-based poverty indicators in recent landmark publications such as OECD, 2008 and 2011, has also invested significant effort into the development of a range of relevant indicators to form part of a 'dashboard' to be monitored.
} 
environment, and a necessary tool in order to monitor 27 different national situations. The prospects of progress, including towards that target, have been seriously compromised by the economic crisis and its aftermath, as we shall see.

\section{Patterns of income poverty in Europe before the crisis}

We now discuss the evidence on the extent and nature of poverty and social exclusion in Europe and how that has evolved over time. The scale of the economic crisis from 2007-8 onwards means that it is worth focusing first on the situation before its onset, then look back on how poverty in Europe had evolved up to that point, and then turn to how it has been affected by the crisis. For the picture immediately before (and through) the crisis we can rely on the data on the relevant poverty and inclusion indicators produced by Eurostat and included in their database on social inclusion indicators, drawn from the EU Statistics on Income and Living Conditions (EU-SILC) data-gathering exercise covering all the EU Member States.

Starting with the at-risk-of-poverty poverty measure, Table 1 shows the percentage of persons in households falling below $60 \%$ of the median disposable household income in their country in the EU-SILC results for $2008 .{ }^{4}$ This varied from a low of $9 \%$ in the Czech Republic to a high of $26 \%$ in Latvia. Other countries with a rate well above average were Bulgaria, Estonia, Greece, Spain, Lithuania and Romania, while Italy, Portugal and the UK were also above the average. Austria, Belgium, Cyprus, Croatia, Germany, Ireland, Malta and Poland were around the average. Denmark, Finland, France, Luxembourg, Hungary, Slovenia and Sweden were well below the average, while the Netherlands and Slovakia had rates nearly as low as the Czech Republic. (Corresponding figures for $40 \%, 50 \%$ and $70 \%$ of the median are also included in the social inclusion database, and sometimes show different rankings of individual countries.)

[Table 1 here]

\footnotetext{
${ }^{4}$ Note that the income data obtained in EU-SILC generally refers to the previous calendar year, except in the case of Ireland and the UK.
} 
About $63 \%$ of the persons in households below the $60 \%$ threshold live in Germany, France, Italy, Spain and the UK, simply because these are the countries where a very substantial share of the EU population lives. The enlargement of the EU in 2004 did not increase the overall percentage at risk of poverty vis-à-vis relative income thresholds: the 10 new member states had considerably lower average incomes than the previous EU-15 but similar relative poverty rates on average - though Bulgaria and Rumania, joining subsequently, have relatively high rates. The levels of the countryspecific relative thresholds were very different indeed: in Austria, Belgium, Germany and the Netherlands the threshold for a single person household at that point was about $€ 10$ 11,000 , compared to only $€ 4,000$ in Latvia and Lithuania and less than $€ 2,000$ in Romania (having taken differences in purchasing power into account). Were one to instead use the same income threshold across all countries - set for example at $60 \%$ of median income across the EU as a whole - this would give very different results in terms of poverty rates and where the poor in the EU are located, with a much higher proportion in Eastern Europe and a substantially lower share in "Continental Europe" and the UK.

\section{Income poverty dynamics and persistence}

Household incomes change over time, and it is important to be able to distinguish those who move in and out of low income from those who are persistently in that situation. This requires longitudinal data following the same individuals over time, which was central to the design of the ECHP, whereas EU-SILC has a more modest rotating panel element. This does however allow the "persistent at-risk-of-poverty" rate, which is included among the EU's social inclusion indicators and defined as the percentage below the $60 \%$ threshold in the current year and in at least two of the preceding three years, to be produced. Table 2 shows these figures based on the $60 \%$ median threshold, for the countries for which this indicator is available. This persistent at-risk-of-poverty rate ranges from as low as 3-5\% in the Czech Republic, Denmark, Slovakia and Sweden up to $13 \%$ in Cyprus, Estonia, Greece and Portugal, with the average for the EU-15 being about half the at-risk-of-poverty rate. The cross-country differences in persistent poverty are even greater than those in poverty measured in a particular year, because in the 
countries with high poverty rates at a point in time those below the threshold in a given year are also more likely to remain so.

[Table 2 here]

Some comparative studies of income poverty dynamics have made use of the longer time-windows provided by the ECHP and by national panels (see for example Whelan et al 2000, Layte and Whelan 2002, OECD, 2004, Whelan and maître, 2006b, Valetta, 2006). These show what the OECD has aptly summarised as the apparent paradox that poverty is both fluid and characterised by long-term traps. Many spells in poverty are short and represent only transitory set-backs, and the number of people who are poor for an extended period of time is much lower than the number of people who are poor at one specific point in time. On the other hand, the typical year spent in poverty is lived by someone who experiences multiple years of poverty and whose longer-term income is below the income poverty threshold. The substantial degree of income mobility observed from one year to the next thus has to be interpreted with care, and does not mean that poverty is mostly a transient phenomenon.

\section{Levels of material deprivation}

It is helpful to complement the perspective on poverty provided by income-based measures with information on non-monetary indicators of deprivation also obtained from surveys for the same households, and for this purpose one can draw on the indicator included in the EU's Social Inclusion set also drawn from EU-SILC as described earlier. Table 3 shows the percentage experiencing deprivation of 3 or more of the nine items included in this index, which is taken to represent material in the EU's indicator set, and also the percentage deprived of 4 or more which is taken to represent "severe" material deprivation (and enters into the 2020 poverty reduction target as described earlier). We see that there is much more variation across the member states in the extent of material deprivation than in relative income poverty. The deprivation rate ranges from as low as $5 \%$ in Sweden and Denmark up to $50 \%$ or more in Bulgaria and Romania, while the percentage severely deprived goes from $1-2 \%$ in Denmark and Sweden up to $41 \%$ in 
Bulgaria. These differences in the prevalence of deprivation are strongly related to those in average income across the member states, though other factors are also clearly at work as discussed below.

[Table 3 here]

The EU's official target for poverty reduction by 2020 combines low income measured against country-specific relative standards with this measure of severe material deprivation and with the extent of household 'joblessness', as described earlier. Table 4 compares the distribution across countries of the population identified in this way as 'experiencing poverty and social exclusion' with the distribution of those simply below the country's $60 \%$ of median income threshold. We see that the differences are not in fact very marked: although the percentage in the countries with the lowest average incomes notably Bulgaria and Romania - is higher than with purely relative country-specific income thresholds, more than $60 \%$ of the target population is still in France, Germany, Italy, Spain and the UK. This reflects the way the target itself is framed, to include those meeting any one of the three criteria, so that those below the relative income threshold in those large countries continue to dominate. If one instead adopted the alternative approach explored in some studies which identify those both below the relative income thresholds and experiencing deprivation as 'consistently poor', a much higher proportion of those seen below the country's relative income threshold are also experiencing deprivation in the lower-income countries of Eastern Europe, so these countries would account for a larger share of the overall 'consistently poor' population.

[Table 4 here]

\section{Poverty and the economic crisis}

The onset of the financial and economic crisis from 2008, initially in the USA but quickly impacting on European countries, had profound effects on economic growth and employment and on poverty and social exclusion. However, as the study of the impact of the 'Great Recession' on poverty and inequality by Jenkins et al (2012) brought out, these effects varied widely across countries. This was firstly because the impact on levels 
of national income and employment were very different, with countries such as Ireland, Spain, Portugal and after some time Greece seeing pronounced declines in national output and income whereas others such as Germany experienced much more muted GDP and employment effects. Secondly, the 'automatic stabilisers' in tax and transfer systems operated to offset the impact of declining market income on disposable household incomes to varying degrees. Finally, the way governments responded to the crisis and associated fiscal deficits also had major consequences for the extent to which lowerincome households were either protected from or exposed to the worst effects of the crisis and its aftermath.

The poverty and social exclusion indicators employed to this point in capturing the pre-Crisis situation across the EU also allow a picture of the impact of the Crisis to be seen, and brings out in particular how much this varies not only across countries but also depends on the nature of the poverty and exclusion measure one employs. Table 5 shows the levels of three indicators from EU-SILC and how these changed from 2008 and 2014, namely the at-risk-of-poverty rate based on $60 \%$ of the country's median income, the 'anchored' poverty rate based on income thresholds kept unchanged at their 2005 purchasing power (i.e. uprated only for changes in consumer prices from then onwards), and the material deprivation rate also described earlier. We see first that relative income poverty rose only marginally if one focuses on the average rate across the EU, from $16.6 \%$ to $17.2 \%$. While some countries saw quite substantial increases - with the rate in Greece, Croatia, Luxembourg, Romania and Sweden rising by 2 percentage points or more - there were also countries that saw declines, such as Austria, Estonia, Ireland, Cyprus, Latvia, Lithuania and the UK. If one were to rely on this poverty measure, the overall impact of the Crisis across the EU would be seen as rather modest.

[Table 5 here]

This of course reflects the purely relative nature of the measure, and its one-forone linkage to movements in median income: if median income declines, as it did in the countries hardest-hit by the Crisis, so does the poverty threshold. If instead one employs an income poverty threshold that is held fixed in purchasing power terms, then the picture 
for the worst-affected countries is a good deal more negative. The anchored poverty rate also shown in Table 5 increases for Spain, Italy, Luxembourg, Hungary, the Netherlands, Portugal, and Slovenia, even more sharply for Ireland and Cyprus, and by a remarkable $24 \%$ in the case of Greece. (This poverty threshold is anchored to the real level in 2005, and the significant income growth that occurred between then and 2008 in Greece, Ireland, Portugal and Spain means that there would be even greater increases in the proportion falling below thresholds anchored just before the Crisis.)

Table 5 also shows what happened to material deprivation, in terms of the percentage experiencing deprivation of at least three out of the nine items included in the index. We see that this rose very sharply in Ireland, Greece, Spain and Cyprus whose government finances were so badly hit by the Crisis that they had to be 'bailed out' by the EU and IMF, and also increased in Portugal, the other member state requiring such a bail-out, as well as in Denmark, Hungary, Italy, Lithuania, and the UK. Material deprivation fell markedly over this period only in Bulgaria, Finland, Slovakia and Poland. The impact of the Crisis on poverty and social exclusion was clearly much more severe in some countries than in others, but against a counter-factual of rising living standards and declining material deprivation in the absence of such a deep recession the impact was broad-ranging.

In terms of the EU's headline 'at risk of poverty and social exclusion', the impact

of the crisis has been that the target number has risen rather than fallen - from 116 million to over 120 million persons. This is affected by increasing household joblessness as well as the at-risk-of-poverty and material deprivation elements of the target we have discussed, with the large increases in Spain, Italy and the UK - partly offset by a substantial decline in Poland - being particularly important. The ambitious original target, to reduce poverty and social exclusion by 20 million by 2020 , has not been abandoned but now appears very much more challenging.

\section{Who is poor and why?}

While EU countries differ in the overall proportion falling below relative income thresholds, are the types of individuals and households affected very similar from one country to the next? The profile of those living in poverty has been analysed in some 
depth both in individual countries and in an EU-wide context, highlighting as high-risk those with low levels of education and skills, the unemployed, people with disabilities, single parents, large families, the elderly, children, ethnic minorities, migrants, and refugees. These are also the types of "vulnerable groups" identified by the National Action Plans on Social Inclusion prepared by EU member states as part of the Social Inclusion Process. The information from EU-SILC in the EU's social inclusion indicators database allows one to compare the poverty risk using the $60 \%$ of median threshold facing persons with different individual and household circumstances, and some broad patterns are worth noting in that regards in terms of commonality versus differentiation across countries before the crisis.

Focusing on age, for example, the average at-risk-of-poverty rate for children across the EU as a whole was $20 \%$, higher than the corresponding figure for all persons which was $16.6 \%$; the rate for children was also above-average in most countries, though not in Croatia, Cyprus, Denmark, Estonia, Finland, Germany, Latvia and Slovenia. The average poverty rate for older persons (aged 65 or over) was about 19\%, again considerably higher than for all persons but also with exceptions, in this case the Czech Republic, Germany, France, Luxembourg, Hungary, the Netherlands, Poland and Slovakia. Looking at household composition, households comprising a working-age couple with no children are much less likely to be below the $60 \%$ threshold than single working-age adults in every country, but the gap is much wider in some countries than in others. For couples with children, there is generally little difference in risk for those with one child versus couples with two children. Indeed, the level of risk they face is often similar to that for couples with no children. However, the risk is considerably higher for those couples with three or more children than for those with one or two children. Single parents face much higher risks than couples with one or two children, and most often are at greater risk of falling under the poverty line than couples with three or more children, but the gap between these groups varies a good deal.

There is even more variation when one focuses on other groups that are generally thought to be at high risk. Table 6 compares the at-risk-of-poverty rates for adults who are unemployed, retired or inactive with those who are employed (as an employee or selfemployed). We see that the unemployed face a significantly heightened risk everywhere, 
but the extent of that gap varies widely: the rate for the unemployed is as much as 7 or 8 times that of the employed in Belgium, Bulgaria, Denmark, Finland, Germany, Estonia, Hungary, the Netherlands, Malta, Slovenia and Slovakia, and even greater in the Czech Republic. On the other hand, it is no more than 3 or 4 times the rate for the employed in Greece, Spain, Poland, Portugal and Romania. The rate for the employed is particularly high in this latter group, in part because of the still-substantial proportion of the workforce employed in agriculture.

\section{[Table 6 here]}

This mix of commonalities versus variation across countries in "relative risk", in the risk faced by specific groups compared with the overall poverty risk in the country in question, is also seen if one focuses on educational attainment, and has major implications for our understanding of the processes at work. Clearly there are some characteristics of individuals and households that predispose some people to have a relatively low level of income compared to their needs, with limited education/skills and the makeup of the household the most obvious examples. However, the extent to which these manifest themselves in high at-risk-of-poverty rates, either in terms of risk level or relative to other groups in the same country, depends on other factors, notably labour markets and institutional settings that amplify versus compensate for these disadvantages. For example, the "penalty" facing an unemployed individual in terms of heightened poverty risk depends on whether they have dependents, whether there are others in the household at work, and how the welfare state and its institutions cushion the impact of unemployment, most importantly through social protection. To take another example, single parents generally face a much higher risk of falling into poverty than couples with children, but in many countries it is not the fact of living in a single-parent household per se that increases risks, but rather the employment status of that parent; in some countries, the poverty rate among single parents with a job is not that much different from the overall rate for couples with children, and the level of support provided to children in single parent households by the welfare and tax systems also plays an important role (OECD, 2005). 
Using longitudinal data to look at the variation in poverty across individuals and households over time helps to shed light on the processes at work. Econometric modeling of poverty dynamics - transitions into and out of poverty - in the ECHP versus the US PSID suggested that changes in household structures may be less important, and labour market 'events' more important, in that respect in European countries than in the USA. Separation or divorce is the most common family-related event associated with falling below the poverty line in both, whereas marriage brought more people above the poverty line in North America than in the EU-15. There was a particularly strong association between job-related events (such as a change in the number of employed persons in the household, in the number of months they worked, or in earnings) and poverty transitions in the EU, and changes in social transfers were also important (OECD, 2005; see also Layte and Whelan, 2002, Valletta, 2004, Fouarge and Layte, 2005). Comparing countries grouped into standard welfare 'regimes', the high level of poverty 'escapes' and short poverty durations in the social democratic/Scandinavian countries were distinctive.

These variations across countries in the 'relative risk' of poverty facing those living in different household types and circumstances, and in the types of factor associated with poverty persistence versus escape, have important implications for policy. They serve to highlight first of all that some institutional settings - relating not just to social protection but also in the labour market - are much more effective than others in reducing the risk of poverty for individuals and households whose characteristics and circumstances leave them vulnerable, but that individual countries are often more effective in addressing the needs of one group than another. They also bring out the complexity of the causal processes underpinning such vulnerability and its impacts, so that a policy response that focuses on just one area or domain, however important, is unlikely to be adequate. These are points to which we return having addressed the question that is in a sense over-arching: why is poverty overall much higher in some European countries than others?

\section{Why is poverty higher in}

There has been a good deal of research focused on why there is considerably more poverty, measured via relative income poverty thresholds, in some EU countries than in 
others. While a comprehensive overall explanation has yet to emerge, one can point to some of the factors at work. An obvious place to start is with economic growth and employment, which in a globalised economy are seen more than ever as the sine qua non for reducing poverty. However, it is not as easy as might be expected to detect very strong links empirically. Comparing poverty risk levels and employment rates across the EU before the crisis, one sees only a rather weak relationship, as Marlier et al (2006) highlighted. Although below-average employment does most often go with aboveaverage poverty risk or vice versa, there are also countries that combine below-average employment with below-average poverty risk (notably Belgium, Hungary, Malta and Luxembourg), and others with high employment and above-average poverty risk (such as Ireland, Portugal and the UK). In a similar vein, only some of the countries that experienced rising employment rates in the decade up to the crisis saw the at-risk-ofpoverty rate decline, with others seeing it stable or even rising. Indeed, Cantillon (2011) has emphasized that the fact that in broad terms little progress was made in reducing poverty - captured in this way - even in times of reasonably robust economic growth and strong employment has fundamental implications for how one thinks about anti-poverty policy (see also Cantillon and Vandenbroucke, 2014).

This is certainly related to the way that the at-risk-of-poverty threshold itself moves over time, with increasing employment rates likely to drive increases in the median to which the relative income thresholds are linked. Using a poverty threshold anchored in real terms (i.e. only updated by inflation), most of the countries that had increasing employment rates did see a decline in poverty. In addition, as Förster and d'Ercole (2005) point out, countries with higher employment rates (in particular for women) display lower market income poverty rates - that is, before taxes and transfers have been taken into account - so transfers and taxes do not have as much work to do in reducing poverty. However, it is still very important to understand why an increase of the employment rate may not lead to corresponding reductions in the numbers below relative income thresholds. This is firstly because the jobs created may not pay enough to lift households out of poverty, particularly given high marginal taxes and benefit withdrawal rates may mean that there is little net gain. The second consideration is that those below the poverty threshold may not be the ones to benefit from the jobs coming on stream: 
between 2001 and 2005, for example, the proportion of working-age adults living in jobless households remained essentially unchanged in the EU despite substantial increases in the numbers at work.

Another focus in seeking to understand cross-country differences in poverty rates is on the size of particularly vulnerable groups, and the extent to which higher/lower poverty is related to the overall size of such groups. If one looks for example at the proportion in household types that are typically thought of as vulnerable - elderly singles, elderly couples, single parents, and couples with three or more children - then there is indeed significant variation across EU countries in the size of each of these groups. However, often countries that are above average in one or two of the groups are below average on the others, and there is no obvious significant relationship between the overall importance of these groups and country's at-risk-of-poverty rate. For example, Denmark and Sweden have above-average numbers in these groups but low poverty rates, while the opposite is the case for Greece, Spain and Portugal. This also reflects the fact that, as we have seen, there is a good deal of variation across countries in terms of the risks of falling into poverty that is associated with membership of such a group: both the household setting and the country's income support and broader welfare institutions can very much alleviate the poverty risk associated with such characteristics. Differences in demographic profiles can only go so far in explaining differences in poverty rates across countries, and their effects are difficult to disentangle from the institutional settings in which they are found.

Among such institutional features, the level of social welfare expenditures is a commonly-used indicator for "welfare effort" and seen as central in preventing and addressing poverty. Comparing social protection expenditures as a percentage of GDP with poverty risk levels across the pre-crisis EU, the relationship is rather weak - the same level of poverty risk can be seen in countries with very different levels of social welfare expenditures - although it is noteworthy that no EU-15 country had a low risk-ofpoverty rate without significant social spending. The way the social protection system is structured as well as the overall level of spending is clearly important. Some countries achieve considerably larger reduction in poverty than others per euro spent by targeting low-income groups more effectively, though certain types of targeting mechanisms can 
have negative side-effects in terms of incentives and behavior that are a significant focus for research.

Rather than simply looking at cross-sectional comparisons, one can also look for clues on what underpins differences in poverty by looking at individual country experiences over time, in particular as specific policies or broader strategies are implemented. This is difficult to do, not least because the linkage between implemented policies and outcomes is often very hard to trace, and policies are framed in a way that is specific to the each country. However, it may still be possible to draw some general conclusions. In relation to the strategy of tackling poverty by concentrating on growth and jobs, we have already referred to the mixed experience in terms of trends in at-riskof-poverty rates as overall employment rates have moved up or down. Some Member States with relatively high overall employment rates still have above-average proportions of working-age persons living in jobless households, and groups such as the long-term unemployed, migrants, and those with disabilities may not benefit from increases in overall employment rates. Even where the number of workless households does decline, the impact on poverty may be offset by a reduction of the poverty-reducing effectiveness of taxes and transfers, in the face of fiscal pressures.

Studies focused on explaining cross-country variation in material deprivation rather than relative income poverty have shown that differences in income levels play an important role, but that macroeconomic and institutional variables are also important.

Overall, differences in poverty and social exclusion across European countries may best be seen not in terms of welfare states versus markets, but rather in the interactions between them. Much of the cross-national variations in poverty rates persists even when differences in demographic structures been taken into account, and householdlevel and labour market outcomes are not independent of welfare state structures. As Ritakallio and Fritzell (2004) concluded, "it is clearly in the nexus of family and the welfare state that we find the most marked difference between the Nordic countries and the continental ones" (p. 20). This may be taken as a reasonable summary of the current state of knowledge, particularly if seen as the "family-labour market-welfare state" nexus. 


\section{The multidimensional nature of poverty and social exclusion and strategy responses}

As noted at the outset, while this chapter has focused for the most part on indicators of low income and deprivation, it is worth emphasizing the multifaceted nature of poverty and social exclusion, both at the research and policy levels. This is reflected in the fact that the EU's Social Inclusion indicators also include other critical dimensions such as education, housing and health. Analysis of the inter-relationships between some of these non-monetary dimensions and income is still at a relatively early stage, but it is clear that the rankings of countries can vary a good deal across them. Marlier et al (2006), for example, show that country rankings on four of the indicators - income poverty risk, long-term unemployment, the proportion of working-age adults living in jobless households, and the share of persons aged 18-24 who have only secondary education and are not currently enrolled in school or training programs - often differ substantially. Comparative studies adopting an explicitly multidimensional focus (such as Alkire, Apablaza and Jung, 2014, and Whelan et al, 2014 implementing the 'adjusted headcount' approach with EU-SILC data) have brought out that both the nature of multidimensional poverty and the extent to which it is socially stratified varies by national average level of income.

The range of complex phenomena that come under the heading of social exclusion cannot be treated simply as by-products of low income and relative income poverty. Poor housing, neighbourhood deprivation, poor health and access to health services and low levels of education are clearly related to low income but have to be both understood and addressed in policy terms as distinct aspects of social exclusion. The limited overlap between them in a cross-sectional context means that the very sizeable numbers conventionally measured as at-risk-of-poverty in income terms - from one-tenth to onefifth of the population in EU-25 countries - are not to be seen as distinct, separate groups removed from the rest of their respective society. As far as poverty and exclusion are concerned, the evidence suggests that a sharp dichotomy between a "comfortable" majority and an excluded minority may not be the most helpful way to understand the processes at work or framing effective strategies to combat them. On the other hand, it represents a challenge both analytically, in trying to tease out the complex processes at 
work, and in framing strategies that successfully address these distinct but inter-related manifestations of exclusion.

The current orientation of the EU towards addressing poverty reflects its multifaceted nature, and is framed in terms of a Social Investment Strategy. Social investment is seen by proponents as setting out the preferred institutional structuring for the welfare state, towards which the (more or less fundamental) restructuring of existing institutions and policies should be directed (see for example Vandenbroucke, Hemerijck and Palier, 2011, Morel, Palier and Palme, 2012, Hemerijck and Vandenbroucke, 2012). While the conceptual distinction between 'investment' versus consumption in this context may be open to argument (see for example Nolan, 2013), the emphasis in this strategy on addressing the deep-seated barriers faced by those from disadvantaged backgrounds is an important element in a long-term strategy aimed at reducing poverty. This still leaves the very real challenge of framing policies that hold out some prospect of significantly reducing poverty in the short- to medium-term, the horizon over which the EU has set itself a concrete target. While social policies as commonly understood have a major role to play, poverty reduction has to be seen as a central aim of economic policy if there is to be substantial progress towards those goals. 


\section{References}

Alkire, S and J. Foster (2011), 'Understandings and Misunderstandings of Multidimensional Poverty Measurement', Journal of Economic Inequality, 9 (2), 289314.

Alkire, S., M. Apablaza and E. Jung (2014), Multidimensional poverty measurement for EU-SILC countries, OPHI Working Paper 36c, Oxford: Oxford Department of International Development.

Atkinson, A. B. (2003), 'Multidimensional Deprivation: Contrasting Social Welfare and Counting Approaches', Journal of Economic Inequality, 1 (1), 51-65.

Atkinson, Anthony B., B. Cantillon, E. Marlier and B. Nolan, (2002), Social Indicators: The EU and Social Inclusion, Oxford University Press: Oxford.

Cantillon, B. (2011), 'The Paradox of the Social Investment State: Growth, Employment and Poverty in the Lisbon Era', Journal of European Social Policy 21 (5), 432-449.

Cantillon, B. and F. Vandenbroucke (eds), (2014), For Better For Worse. For Richer For Poorer. Labour market participation, social redistribution and income poverty in the EU, Oxford: Oxford University Press.

Boarini, R., and M. Mira d'Ercole (2006), Measures of material deprivation in OECD countries. OECD Social Employment and Migration Working Papers No. 37. Paris: OECD.

Bourguignon, F. and S. Chakravarty (2003), 'The Measurement of Multidimensional Poverty', Journal of Economic Inequality, 1 (1), 25-49.

Eurostat (2000), Income, Poverty and Social Exclusion in Member States of the European Union, Luxembourg: Office for Official Publications of the European Communities.

Fouarge, D. and R. Layte, (2005), 'Welfare Regimes and Poverty Dynamics: The Duration and Recurrence of Poverty Spells in Europe', Journal of Social Policy, 34 (3), $407-426$.

Förster, M. and M.M. d'Ercole (2005), Income Distribution and Poverty in OECD Countries in the Second Half of the 1990s, OECD Social, Employment and Migration Working Papers 22, Paris: OECD.

Guio, A.-C. (2005), Material deprivation in the EU, Statistics in Focus 21/2005, Eurostat, Luxembourg: Office for Official Publications of the European Communities. 
Guio, A.-C. (2009), What can be learned from deprivation indicators in Europe?

Eurostat methdologies and working paper, Luxembourg: Office for Official Publications of the European Communities.

Guio, A.-C. and Maquet, E. (2007), 'Material Deprivation and Poor Housing', in Comparative EU Statistics on Income and Living Conditions: Issues and Challenge, Eurostat, Luxembourg: Office for Official Publications of the European Communities.

Guio, A-C, Fusco, A. and Marlier, M. (2009), A European Union Approach to Material Deprivation using EU-SILC and Eurobarometer Data, IRISS Working Paper, Luxembourg: CEPS/INSTEAD.

Hemericjk, A. and F. Vandenbroucke (2012), 'Social Investment and the Euro Crisisis: The Necessity of a Unifying Social Policy Concept', Intereconomics, 47 (4), 200-206.

Jenkins, Stephen, A. Brandolini, J. Micklewright and B. Nolan (2013), The Great Recession and the Distribution of Household Income, Oxford: Oxford University Press.

Kakwani, Nanak and J. Silber eds. (2008), Quantitative Approaches to Multidimensional Poverty Measurement, New York: Palgrave Macmillan.

Kangas, O. and Ritakallio, V. (1998), 'Different Methods - Different Results? Approaches to Multidimensional Poverty', in Andress, H.J., ed., Empirical Poverty Research in a Comparative Perspective, Ashgate: Aldershot.

Layte, R. and C.T. Whelan (2002), 'Cumulative Disadvantage or Individualization: A Comparative Analysis of Poverty Risk and Incidence’, European Societies, 4 (2), 209233.

Marlier, E., A.B. Atkinson, B. Cantillon and B. Nolan (2006), The EU and Social Inclusion: Facing the Challenges, Bristol: Policy Press.

Morel, N., B. Palier and J. Palme eds. (2012), Towards a Social Investment State? Ideas, Policies and Challenges, Bristol: Policy Press.

Nolan, B. (2013), 'What Use is Social Investment?', Journal of European Social Policy, 23 (5), 459-468.

Nolan, B. and Whelan, C.T. (2007), 'On the multidimensionality of poverty and social exclusion'. In Micklewright, J. and Jenkins, S. (Eds.), Poverty and Inequality: New Directions. Oxford: Oxford University Press.

Nolan, B. and Whelan, C.T. (2011), Poverty and Deprivation in Europe, Oxford: Oxford University Press.

OECD (2004), Employment Outlook 2004, Paris: OECD. 
OECD (2008), Growing Unequal, Paris: OECD.

OECD (2011), Divided We Stand, Paris: OECD.

O'Higgins, M. and Jenkins, S.P. (1990), 'Poverty in EC: Estimates for 1975, 1980 and 1985', in R. Teekens and B.M.S. van Praag (eds.) Analysing poverty in the European Community, Eurostat News Special Edition, Luxembourg: Office for Official Publications of the European Communities.

Ravallion, M. (2011), 'On Multidimensional Indices of Poverty', Journal of Economic Inequality, 9 (2), 235-248.

Townsend, P. (1979), Poverty in the United Kingdom, Harmondsworth: Penguin.

Vandenbroucke, F., A. Hemerijck and B. Palier (2011), The EU Needs a Social Investment Pact, OSE Paper Series, Opinion paper No. 5, Obsevatoire Social Europeene, Brussels.

Valetta, R. (2006), 'The Ins and outs of Poverty in Advanced Economies: Government Policy and poverty Dynamics in Canada, Germany, Great Britain and the United States', Review of Income and Wealth, 52 (2), 261-284.

Whelan, C. T., Layte, R. and Maitre, B. (2004), 'Understanding the Mismatch between Income Poverty and Deprivation: A Dynamic Comparative Analysis', European Sociological Review, 20 (4), 287-302.

Whelan, C. T. and Maître, B. (2005), 'Vulnerability and Multiple Deprivation Perspectives on Economic Exclusion in Europe: A Latent Class Analysis', European Societies, 7 (3), 423-450.

Whelan, C. T. and Maître, B. (2006a), 'Economic Vulnerability, Multidimensional Deprivation and Social Cohesion in the Enlarged European Community', International Journal of Comparative Sociology, 46 (3), 216-239.

Whelan, C. T. and Maître, B. (2006b), 'Comparing Poverty and Deprivation Dynamics: Issues of Reliability and Validity’, Journal of Economic Inequality, 4 (2), 303-23.

Whelan, C.T., Nolan, B. and Maître, B. (2014), 'Multidimensional Poverty Measurement in Europe: An Application of the Adjusted Headcount Approach', Journal of European Social Policy, 24 (2), 183-197. 
Table 1: Percentage At Risk of Poverty, EU-SILC 2008

\begin{tabular}{lc}
\hline & $\%$ \\
\hline Belgium & 14.7 \\
Bulgaria & 21.4 \\
Czech Republic & 9 \\
Denmark & 11.8 \\
Germany & 15.2 \\
Estonia & 19.5 \\
Ireland & 15.5 \\
Greece & 20.1 \\
Spain & 20.8 \\
France & 12.5 \\
Croatia & 17.3 \\
Italy & 18.7 \\
Cyprus & 15.9 \\
Latvia & 25.9 \\
Lithuania & 20.9 \\
Luxembourg & 13.4 \\
Hungary & 12.4 \\
Malta & 15.3 \\
Netherlands & 10.5 \\
Austria & 15.2 \\
Poland & 16.9 \\
Portugal & 18.5 \\
Romania & 23.4 \\
Slovenia & 12.3 \\
Slovakia & 10.9 \\
Finland & 13.6 \\
United Kingdom & 12.2 \\
EU average (27 countries) & 18.7 \\
\hline
\end{tabular}


Table 2: Percentage Persistently At Risk of Poverty, EU-SILC 2008

\begin{tabular}{lc}
\hline & \% Persistently Poor \\
\hline Belgium & 9 \\
Bulgaria & $:$ \\
Czech Republic & 3.9 \\
Denmark & 4.9 \\
Germany & 7.2 \\
Estonia & 13.6 \\
Ireland & $:$ \\
Greece & 13 \\
Spain & 11 \\
France & $:$ \\
Croatia & $:$ \\
Italy & 12.7 \\
Cyprus & 9.9 \\
Latvia & 12.6 \\
Lithuania & 10.9 \\
Luxembourg & 8.4 \\
Hungary & 7.7 \\
Malta & 7.7 \\
Netherlands & 6.4 \\
Austria & 5.6 \\
Poland & 10.4 \\
Portugal & 13.1 \\
Romania & $:$ \\
Slovenia & 7.7 \\
Slovakia & 4.9 \\
Finland & 6.8 \\
Sweden & 2.6 \\
United Kingdom & 8.5 \\
EU (27 countries) & \\
\hline
\end{tabular}


Table 3: Percentage Experiencing Material Deprivation, EU-SILC 2008

\begin{tabular}{lcc}
\hline & \% Material Deprivation & \% Severe Material Deprivation \\
\hline Belgium & 11.6 & 5.6 \\
Bulgaria & 55 & 41.2 \\
Czech Republic & 16.2 & 6.8 \\
Denmark & 5.4 & 2.0 \\
Germany & 13 & 5.5 \\
Estonia & 12.4 & 4.9 \\
Ireland & 13.6 & 5.5 \\
Greece & 21.8 & 11.2 \\
Spain & 10.8 & 3.6 \\
France & 13.1 & 5.4 \\
Croatia & $:$ & $:$ \\
Italy & 16.1 & 7.5 \\
Cyprus & 24.9 & 9.1 \\
Latvia & 35.7 & 19.3 \\
Lithuania & 23 & 12.5 \\
Luxembourg & 3.5 & 0.7 \\
Hungary & 37.1 & 17.9 \\
Malta & 13.7 & 4.3 \\
Netherlands & 5.2 & 1.5 \\
Austria & 13 & 5.9 \\
Poland & 32.3 & 17.7 \\
Portugal & 23 & 9.7 \\
Romania & 50.3 & 32.9 \\
Slovenia & 16.9 & 6.7 \\
Slovakia & 27.8 & 11.8 \\
Finland & 9.1 & 3.5 \\
Sweden & 4.6 & 1.4 \\
United Kingdom & 11.3 & 4.5 \\
& & \\
EU (27 countries) & 17.5 & 8.5 \\
\hline
\end{tabular}


Table 4: People at risk of poverty or social exclusion, EU-SILC 2008

\begin{tabular}{lccc}
\hline & $\begin{array}{c}\text { At risk of poverty and social exclusion } \\
\text { \% of }\end{array}$ & $\begin{array}{c}\text { At risk of poverty } \\
\text { \% of EU total }\end{array}$ \\
\hline Belgium & 2194 & 1.88 & 1.91 \\
Bulgaria & 3421 & 2.93 & 2.01 \\
Czech Republic & 1566 & 1.34 & 1.14 \\
Denmark & 887 & 0.76 & 0.79 \\
Germany & 16345 & 14.02 & 15.23 \\
Estonia & 291 & 0.25 & 0.32 \\
Ireland & 1050 & 0.90 & 0.84 \\
Greece & 3046 & 2.61 & 2.69 \\
Spain & 11124 & 9.54 & 11.57 \\
France & 11150 & 9.57 & 9.28 \\
Croatia & $:$ & $:$ & $:$ \\
Italy & 15099 & 12.95 & 13.70 \\
Cyprus & 181 & 0.16 & 0.15 \\
Latvia & 740 & 0.63 & 0.69 \\
Lithuania & 910 & 0.78 & 0.83 \\
Luxembourg & 72 & 0.06 & 0.08 \\
Hungary & 2794 & 2.40 & 1.51 \\
Malta & 81 & 0.07 & 0.07 \\
Netherlands & 2432 & 2.09 & 2.11 \\
Austria & 1699 & 1.46 & 1.54 \\
Poland & 11491 & 9.86 & 7.81 \\
Portugal & 2757 & 2.37 & 2.42 \\
Romania & 9418 & 8.08 & 6.13 \\
Slovenia & 361 & 0.31 & 0.30 \\
Slovakia & 1111 & 0.95 & 0.72 \\
Finland & 910 & 0.78 & 0.87 \\
Sweden & 1367 & 1.17 & 1.38 \\
United Kingdom & 14069 & 12.07 & 13.93 \\
EU (27 countries) & 116566 & 100.00 & 100.0 \\
\hline
\end{tabular}


Table 5: At Risk of Poverty Rate, Anchored Poverty Rate and Material Deprivation Rate,

EU-SILC 2008 and 2014

\begin{tabular}{|c|c|c|c|c|c|c|c|c|c|}
\hline & \multicolumn{3}{|c|}{ at risk of poverty rate } & \multicolumn{3}{|c|}{ anchored (2005) poverty rate } & \multicolumn{3}{|c|}{ material deprivation rate } \\
\hline & 2008 & 2014 & Change & 2008 & 2014 & Change & 2008 & 2014 & Change \\
\hline & $\%$ & $\%$ & & $\%$ & $\%$ & & $\%$ & $\%$ & \\
\hline Belgium & 14.7 & 15.5 & 0.8 & 15 & 11.9 & -3.1 & 11.6 & 11.8 & 0.2 \\
\hline Bulgaria & 21.4 & 21.8 & 0.4 & : & : & & 55 & 46.8 & -8.2 \\
\hline \multicolumn{10}{|l|}{ Czech } \\
\hline Republic & 9 & 9.7 & 0.7 & 6 & 5.2 & -0.8 & 16.2 & 16.5 & 0.3 \\
\hline Denmark & 11.8 & 11.9 & 0.1 & 11.2 & 9.8 & -1.4 & 5.4 & 7.7 & 2.3 \\
\hline Germany & 15.2 & 16.7 & 1.5 & 13.4 & 15.1 & 1.7 & 13 & 11.3 & -1.7 \\
\hline Estonia & 19.5 & 18.6 & -0.9 & 5.4 & 6.4 & 1 & 12.4 & 19.4 & 7 \\
\hline Ireland & 15.5 & 14.1 & -1.4 & 9.9 & 17.8 & 7.9 & 13.6 & 24.4 & 10.8 \\
\hline Greece & 20.1 & 22.1 & 2 & 18.5 & 42.7 & 24.2 & 21.8 & 39.5 & 17.7 \\
\hline Spain & 20.8 & 22.2 & 1.4 & 16.9 & 20.7 & 3.8 & 10.8 & 17.8 & 7 \\
\hline France & 12.5 & 13.3 & 0.8 & : & $:$ & & 13.1 & 11.9 & -1.2 \\
\hline Croatia & 17.3 & 19.4 & 2.1 & : & : & & : & 33.8 & \\
\hline Italy & 18.7 & 19.6 & 0.9 & 18.3 & 22.8 & 4.5 & 16.1 & 22.4 & 6.3 \\
\hline Cyprus & 15.9 & 14.4 & -1.5 & 10.8 & 19.6 & 8.8 & 24.9 & 36.5 & 11.6 \\
\hline Latvia & 25.9 & 21.2 & -4.7 & 7.4 & 6.5 & -0.9 & 35.7 & 34.6 & -1.1 \\
\hline Lithuania & 20.9 & 19.1 & -1.8 & 5.4 & 5.1 & -0.3 & 23 & 28.3 & 5.3 \\
\hline Luxembourg & 13.4 & 16.4 & 3 & 13.8 & 17.3 & 3.5 & 3.5 & 5 & 1.5 \\
\hline Hungary & 12.4 & 14.6 & 2.2 & 9.5 & 11.9 & 2.4 & 37.1 & 39.6 & 2.5 \\
\hline Malta & 15.3 & 15.9 & 0.6 & 12.5 & 7.5 & -5 & 13.7 & 20.2 & 6.5 \\
\hline Netherlands & 10.5 & 11.6 & 1.1 & 7.7 & 9.9 & 2.2 & 5.2 & 9 & 3.8 \\
\hline Austria & 15.2 & 14.1 & -1.1 & 14.2 & 11.2 & -3 & 13 & 9.4 & -3.6 \\
\hline Poland & 16.9 & 17 & 0.1 & 8.3 & 5.3 & -3 & 32.3 & 22.2 & -10.1 \\
\hline Portugal & 18.5 & 19.5 & 1 & 17 & 20.4 & 3.4 & 23 & 25.7 & 2.7 \\
\hline Romania & 23.4 & 25.4 & 2 & : & $:$ & & 50.3 & 44 & \\
\hline Slovenia & 12.3 & 14.5 & 2.2 & 9.1 & 11.6 & 2.5 & 16.9 & 17.2 & 0.3 \\
\hline Slovakia & 10.9 & 12.6 & 1.7 & 4.8 & 3.2 & -1.6 & 27.8 & 22.2 & -5.6 \\
\hline Finland & 13.6 & 12.8 & -0.8 & 10.9 & 8.1 & -2.8 & 9.1 & 7.9 & -1.2 \\
\hline Sweden & 12.2 & 15.1 & 2.9 & 8.2 & 7.1 & -1.1 & 4.6 & 3.2 & -1.4 \\
\hline \multicolumn{10}{|l|}{ United } \\
\hline Kingdom & 18.7 & 16.8 & -1.9 & 14.8 & 15.8 & 1 & 11.3 & 15.5 & 4.2 \\
\hline \multicolumn{10}{|l|}{ EU (28 } \\
\hline countries) & 16.6 & 17.2 & 0.6 & $:$ & 15.6 & & 17.5 & 18.5 & 1 \\
\hline EU (27 & & & & & & & & & \\
\hline countries) & 16.6 & 17.2 & 0.6 & : & : & & 17.5 & 18.3 & 0.8 \\
\hline
\end{tabular}

Note: Data for Estonia and Ireland for 2013 not 2014 
Table 6: At Risk of Poverty Rate by Activity Status, EU-SILC 2008

\begin{tabular}{lcccc}
\hline & $\begin{array}{c}\text { Employed } \\
\%\end{array}$ & $\begin{array}{c}\text { Unemployed } \\
\%\end{array}$ & $\begin{array}{c}\text { Retired } \\
\%\end{array}$ & $\begin{array}{c}\text { Other inactive } \\
\%\end{array}$ \\
\hline Belgium & 4.8 & 34.8 & 18.3 & 25.6 \\
Bulgaria & 7.5 & 55 & 31.7 & 23.9 \\
Czech Republic & 3.6 & 47.8 & 8 & 12.4 \\
Denmark & 5 & 33.9 & 16.5 & 30.6 \\
Germany & 7.1 & 56.8 & 15 & 22.6 \\
Estonia & 7.3 & 61.3 & 43.3 & 31.9 \\
Ireland & 6.5 & 28.3 & 18 & 26.6 \\
Greece & 14.3 & 36.8 & 20.3 & 26 \\
Spain & 11.2 & 39 & 20.9 & 31.7 \\
France & 6.5 & 39.7 & 9.5 & 24.5 \\
Croatia & 8.3 & 32.2 & 23.5 & 25.6 \\
Italy & 8.9 & 41.8 & 14.8 & 28.6 \\
Cyprus & 6.3 & 21.3 & 46.2 & 20.6 \\
Latvia & 10.5 & 50.9 & 56.2 & 32.6 \\
Lithuania & 9.4 & 52.1 & 32.2 & 34 \\
Luxembourg & 9.4 & 52.2 & 4.9 & 15.9 \\
Hungary & 5.8 & 48.9 & 6.8 & 23.9 \\
Malta & 5.1 & 30.6 & 23.8 & 21.7 \\
Netherlands & 4.8 & 36.3 & 8.3 & 18.8 \\
Austria & 8.5 & 47.3 & 16.7 & 25.4 \\
Poland & 11.5 & 38.8 & 9.6 & 25 \\
Portugal & 11.8 & 34.6 & 20.1 & 28.3 \\
Romania & 17.5 & 42.7 & 19 & 31.8 \\
Slovenia & 5.1 & 37.6 & 17.9 & 21.6 \\
Slovakia & 5.8 & 43.2 & 9.7 & 15.7 \\
Finland & 5.1 & 42.8 & 21.8 & 32.1 \\
Sweden & 6.8 & 39.2 & 14.9 & 27.2 \\
United Kingdom & 8.5 & 54.4 & 28.4 & \\
EU (27 countries) & & & & \\
\hline & & 44.8 & 16.3 & \\
\hline
\end{tabular}


